stay geriatric patients. They last as long as more expensive silicone coated or pure silicone catheters, are more comfortable because they are softer, and are contraindicated only in patients allergic to latex. This view was also shared by Dr Belfield himself a couple of years ago, ${ }^{1}$ and supports the view that a catheter is changed according to patients' needs and not by manufacturer's specification.

Other workers have confirmed that there is no difference in the time between catheter changes with different types despite the apparently smoother surface of the Silastic catheters supposedly minimising encrustation. ${ }^{23}$ Indeed, scanning electronmicroscopy of the surface structure of different catheter materials has shown that the surface of unused siliconised latex is rough. ${ }^{4}$ Some patients are probably "encrustation formers" whatever catheter material is chosen. Alternative methods, such as high fluid intake and acidifying the urine with high dose ascorbic acid, are more effective at reducing blockage.

Our second comment concerns the treatment of "infection." We certainly agree that the addition of antibacterial substances into drainage bags is ineffective in preventing bacteriuria. There are, however, good studies reporting that bladder washouts are also ineffective and probably harmful by further disrupting the already damaged bladder epithelium, thus predisposing the patient to further infection. ${ }^{56}$

Finally, we think that there should have been some comment about local care and about the effect on sex lives. A twice daily local soapy wash to the area, including the first six inches of catheter, and counselling on methods of sexual intercourse are minimum requirements for all patients.

C M CASTLEDEN

P EKELUND

H M DUFFIN

Department of Geriatric Medicine,

Leicester General Hospital

Leicester LES 4PW

1 Belfield PW, Young JB, Mulley GFP. Rejection of catheters BrMed I 1985;291:108-9.

2 Ferric BG, Glen ES, Hunter B. Long-term urethral catheter drainage. BrMed f 1979;ii: 1046-7.

3 Brocklehurst JC, Brocklehurst $S$. The management of indwelling catheters. Br f Urol 1978;50:102-5.

4 Axelsson H, Schonebeck J, Winblad B. Surface structure of unused and used catheters. Scand f Urol Nephrol 1977;11:283.

5 Stickler DJ, Clayton CL, Chawla JC. Assessment of antiseptic bladder washout procedures using a physical mould of the catheterized bladder. Brf Urol 1987:60:413-8.

6 Ellior TSJ, Gopal Rao G, Reid L, Woodhouse K. Long-term urethral cathererisation in the elderly. Br Med $\mathcal{J} 1987 ; 294$ : $1095-6$.

\section{Sexual dysfunction among middle aged women}

SIR,-Dr Madeline Osborn and others (2 April, p 959) highlight the disparity between women with operationally defined sexual dysfunction and those who identified themselves as having a problem. In the first group only $23 \%$ thought they had a problem, while $24 \%$ of those with a self identified problem would have been missed if operationally defined sexual dysfunction had been used alone.

While agreeing that general practitioners should be alert to sexual problems, I wonder how useful the concept of sexual dysfunction is in their day to day work. Surely it is how people feel that matters? A previous study concluded that "it is not the quality of sexual performance but the affective tone of the marriage that determines how most couples perceive the quality of their sexual relations."

For people engaged in research a well defined tool is necessary, but for doctors in primary care the concept of sexual distress would be more useful. The emphasis could then be on recognising such distress, often hidden behind other complaints, and on an attempt to understand the cause in each patient.

The general practitioner is ideally placed to have a psychosomatic approach. For example, in this study vaginal dryness is an operationally defined sexual dysfunction and it is not stated whether any patient is receiving hormone replacement. It is possible that some patients could have accepted help in the form of oestrogen cream, although they could not immediately ask for help with a sexual problem. Such an approach would provide other opportunities for sexual discussion and, hopefully, would reach more women than the small number $(4 \%)$ in this study who were able to ask for help directly.

RUTH SKRINE

Department of Obstetrics and Gynaecology,

Bristol Maternity Hospital,

Bristol BS2 8EG

1 Frank E, Anderson C, Rubenstein D. Frequency of sexual dysfunction in "normal" couples. $N$ Engl $f$ Med $1978 ; 299: 111-5$

SIR,-Dr Madeline Osborn and others (2 April, p 959) are right to draw attention to the incidence of sexual difficulty in middle aged women. However, their findings do not support their conclusions that general practitioners should be alert to detecting sexual dysfunction and that it could be treated by general practitioners or referred to specialists. Neither the study nor any of its references refers to straightforward and generally applicable treatments which are effective.

Since the study showed that only $4 \%$ of women both had a problem and wanted help for it the routine questioning of the other $96 \%$ would be a formidable task of doubtful general acceptability. A more appropriate conclusion might have been that women should feel free to approach their general practitioners for help about sexual dysfunction, and that general practitioners should try to maximise their sensitivity to the needs, ideas, and expectations of their patients of all ages and sexes.

BRIAN Goss

Bungay,

Suffolk NR35 1BZ

\section{Death despite malaria prophylaxis}

SIR,-We have seen a case similar to that described by Dr C J Ellis (2 April, p 952).

A man returned from eight months in Zambia and developed a fever, chills and rigors, and severe diarrhoea. He was given a course of choloroquine by a general practitioner who thought of the diagnosis of malaria, and the patient started this immediately. He had not been taking his prophylaxis of choloroquine and proguanil regularly while abroad.

His symptoms improved during the first 24 hours, but he again became confused and febrile and developed severe diarrhoea on the second day. Another doctor who saw him thought that he might have a viral illness in addition to malaria. It took a retired nursing sister to advise the family to ask for immediate hospital admission, and fortunately this was done.

The patient was unconscious on arrival. Quinine was given intravenously and he made a remarkable recovery. A blood film confirmed 5\% parasitaemia with Plasmodium falciparum.

Malaria should be diagnosed by demonstrating parasites in the peripheral blood film. Genera practitioners in Britain should not attempt to treat malaria empirically without referring the patient to hospital as the treatment is different for P vivax and $P$ ovale infections. We agree with $\mathrm{Dr}$ Ellis that quinine should be used to treat falciparum malaria and that chloroquine should be abandoned.

\section{E L C ONG} E M DUNBAR

Regional Department of Infectious Diseases and

Tropical Medicine,

Monsall Hospital,

Manchester M10 8WR

\section{Clinical carpal scaphoid injuries}

SIR,-I am surprised that the scheme for managing clinical scaphoid injury advocated by Dr M R A Young and colleagues (19 March, p 825) makes no mention of radionuclide bone imaging. It is widely thought that focal increased uptake of bone agent reveals sites of bone injury not shown by conventional radiographs, provided the imaging is performed more than 24-48 hours after the injury. The particular application of bone imaging to scaphoid injury has been described from this department.

It is our practice to perform bone imaging early in the management of patients with scaphoid injury but no fracture apparent on radiographs. Normally the patients can be accepted straight from the accident and emergency department or fracture clinic and return to the clinic the same day with a report. In the past year (1987) 100 such patients were examined. In 57 cases the images were normal, but 35 showed abnormal focal uptake of bone agent. Twenty patients had focal uptake in the scaphoid and 12 in other bones of the carpus, suggesting bony injury at these sites. Three patients had focal uptake confined to areas of degenerative change in the radiographs, and five had diffuse uptake interpreted as soft tissue injury.

Patients with normal uptake may be mobilised and discharged early. The precise meaning of focal uptake in the absence of a fracture or degenerative change in the radiographs is debatable. Focal uptake indicates an area of local hyperaemia or osteoblastic response and may well indicate degrees of bony injury short of a complete fracture. Not all of these patients will be at risk of the complications of a scaphoid fracture, but they merit careful follow up and probably a period of immobilisation.

Bone imaging is a useful, safe, and inexpensive investigation in clinical scaphoid injury when the radiograph is normal and should be available in any hospital with nuclear medicine facilities.

Wessex Regional Department of

J J LANGHAM-BROWN

Nuclear Medicine,

Southampton General Hospital

Southampton SO9 4XY

Rolfe EB, Garvie NW, Khan MA, Ackery DM. Isotope bone imaging in suspected scaphoid trauma. Br $\mathcal{F}$ Radiol 1981;54 $762-7$

\section{Wheelchairs}

SIR,_-Dr John B Young's article (27 February, p 625) contains some inaccuracies.

Firstly, the form AOF5G, recommending supply of a wheelchair, can be signed by a doctor, social worker, occupational therapist, or physiotherapist. Secondly, my copy of the handbook of wheelchairs (MHM408) does not describe 140 models of wheelchairs available from the DHSS: it describes only 66 . Thirdly, the description of the model 9L 
chair is deficient; it may have 11 inch pneumatic tyred rear wheels but if the front wheels are not swivel castors propulsion by the attendant is very difficult. Also model 9L chairs do not have detachable sides, making sideways transfer difficult. Fourthly, the use of polyurethane foam and its hazards have been highlighted recently in the national press. Dr Malcolm Ellis in his article on easy chairs (5 March, $p$ 701) considered the use of fire resistant materials desirable. Fifthly, mention is made of the use of a plywood base board to improve the cushioning effect; plywood is too hard a substance; chip foam is far more suitable. Finally, Dr Young says that electric wheelchairs are heavy, do not fold, and require space. But both models 109 and 103 will fold easily once the batteries have been removed. The same applies to the powered carter's chair, but removing the batteries is more difficult.

It was disappointing to find in the references no mention of the booklet on wheelchairs produced by Mary Marlborough Lodge, which covers both DHSS chairs and those which may be bought privately. ${ }^{1}$ Rookwood Hospital and the Royal Hospital and Home, Putney, have both produced excellent booklets aimed at the professionals and disabled people.

Royal Hospital and Home,

M A TUDOR

Royal Ho
Putney,

London SW 15 3SW

1 Cochrane GM, Wilshire ER, eds. Equipment for the disabled. Wheelchairs. 5th ed. Oxford: Oxfordshire Health Authority, 1982

AUTHOR'S REPLY,-Dr Tudor is misinformed about who can authorise a DHSS wheelchair prescription. Inquiries to staff within the artificial limb and appliance centres confirm that form AOF5G can be signed only by a medical practitioner.

Since I wrote my article the appliance services have started reorganising in preparation for their integration into regional and district health authorities on 1 April 1991. The proposed restructured wheelchair service will place greater emphasis on joint assessments of individual patients by doctors and therapists in district based wheelchair clinics. A new wheelchair prescription form is being produced designed to encourage combined doctor-therapist assessments. There are no plans, however, to change the current practice for the instigating signature being that of a medical practitioner.

Describing wheelchairs is difficult because extensive modifications are available to the basic DHSS wheelchair carcases. The written descriptions of the general purpose wheelchairs high lighted in the article were necessarily brief and confined to essential information about standard wheelchairs. They were amplified by illustrations, one of which clearly shows the swivel front wheel castors and the small thick $121 / 2$ inch diameter rear tyres of the $9 \mathrm{~L}$ wheelchair commented on by Dr Tudor. The fixed front wheels about which Dr Tudor is so concerned are non-standard and available only on request. Detachable sidearms to facilitate sideways transfers are standard on the $8 \mathrm{~L}$ models (as stated in the article) and are also readily available if required for the $9 \mathrm{~L}$ series.

Fire risk for wheelchair users is an important aspect but should be placed in context. An inquiry sent to chief fire officers in England and Wales indicated that there were only 30 deaths among seated disabled people (chairs and wheelchairs) over five years ( $E$ W' $\cdot$. , personal communication) Most of these fires had been caused by lighted materials from tobacco smoking falling on clothes or blankets. Thus a fire resistant wheelchair cushion would provide only minimal additional protection. Of greater value would be a fire proof apron or, especially for disabled people with weak or ataxic arms, a variation of the hookah, both items being commercially available.

It is correct that the electric wheelchairs 109 and 103 can be folded; it would perhaps be more accurate to say that they seldom would be folded as to do so requires removal of the heavy batteries mounted under the chair.

There are several wheelchair booklets available and I selected one, People in Wheelchairs, as being the most useful for the generalist.

St Luke's Hospital,

Bradford,

West Yorkshire BDS 0NA

J B Young

\section{Psychiatric illness among British \\ Afro-Caribbeans}

SIR,-In their leading article Dr Roland Littlewood and Dr Maurice Lipsedge (2 April, p 950) misquoted the findings of our study on self poisoning among people of West Indian origin. We found that from 1979 to 1982 for those aged under 25 the incidence of self poisoning was similar among whites and West Indians, whereas for those aged over 25 West Indians were significantly underrepresented.'

The West Midlands poisons unit has been monitoring trends in self poisoning since 1976..$^{1.4}$ Compared with English born people, Irish and Scottish people of all ages have consistently been overrepresented whereas among those aged over 35 West Indians and Asians (Indian, Pakistani, Bangladeshi) have always been underrepresented. Of current concern is the incidence of self poisoning among young Asian women (aged under 35), which is now over double that among young white women and continues to increase annually by $30 \%$.

JOHN MERRILL JOHN OWENS

West Midlands Poisons Unit,

Dudley Road Hospital,

Birmingham B18 7QH

1 Merrill J, Owens J. Ethnic differences in self-poisoning: a comparison of West Indian and white groups. Brf Psychiatry comparison of

2 Wright N, Trethowan WN, Owens J. Ethnic differences in selfpoisoning. Postgrad Med f 1981;57:792-3.

3 Merrill J, Owens J. Ethnic differences in self-poisoning: a comparison of Asian and White groups. Br $\mathcal{J}$ Psychiatry 1986;148:708-12.

4 Merrill J, Owens J. Self-poisoning among four immigrant groups. Acta Psychiatr Scand 1988;77:77-80.

\section{The need to make rugby safer}

SIR, - Mr N W Valentine and Dr M A De Largy (2 April, p 1005) state that in their spinal injuries unit there have been only two admissions in the past 10 years because of injuries from rugby. There are no records here of a major cervical injury before 1977 , but since then we have had one each season and in 1983-4 we had six schoolboys with radiological evidence of cervical damage. ${ }^{1}$

Since reports from rugby playing communities throughout the world have drawn attention to the increased incidence of cervical injury with paralysis, changes have been made in the laws related to forward play. A surprisingly fatalistic attitude has, however, been adopted to injuries among backs. The problem is usually shrugged away with the remark, "This is a bodily contact game and it isn't possible to remove tackling from it." No explanation is given why the game has changed character.
The Maori side step, known hereabouts as "bursting the tackle," is a highly dangerous manoeuvre where the runner aims himself directly at his tackler. Schoolboy three quarters of my generation were taught to elude the tackle by swerve, side step, dummy, or hand off. All these are safe procedures and involve a move away from the tackler. Nowadays the ball carrier is coached to run deliberately at the tackler, who is coming in with his neck flexed. If the impact of thigh or pelvis is on the flexed neck the result will be catastrophic. The Maori side step is more dangerous than the high tackle and should be banned from schoolboy rugby immediately. Adult rugger could also do without it.

To make matters worse, the changes in the rules in the early 1970s ordained that the backs should stand further apart at scrum and line out. As a result the momentum at impact is greater. This change places greater emphasis on the size and weight of the centres and there has been a gradual disappearance of the lightly built centre who was quick off the mark. Initial acceleration is less important now than size and weight.

An important difference between sustaining a major spinal injury when "diving into shallow water on holiday while inebriated" and becoming paralysed in a school game is the responsibility of the school for the accident. Even in New Zealand some schools have given up rugby. The aim of education is meant to be "Mens sana in corpore sano" not tetraplegia.

J Piggot

Musgrave Park Hospital,

Belfast BT9 7JB

1 McCoy GF, Piggot J, Macafee AL, Adair IV. Injuries of the cervical spine in schoolboy rugby football. $\mathcal{J}$ Bone foint Surg $[B r]$ 1984;66:500-3.

\section{Hypoglycaemia in patients with insulin dependent diabetes}

SIR,-The article by Dr Stig Pramming and colleagues (5 March, p 665) on the effects on the electroencephalogram of hypoglycaemia confirms previous results, but the finding of a blood glucose threshold at $2.0 \mathrm{mmol} / \mathrm{l}$ for electroencephalographic changes cannot be taken as it stands from this study.

The authors state that glucose was measured in plasma; if there was no correction then a plasma glucose value of $2.0 \mathrm{mmol} / 1$ corresponds to a blood glucose value of about $1.5 \mathrm{mmol} / \mathrm{l}$. Secondly, the authors state that a blood glucose value of 2.0 $\mathrm{mmol} / \mathrm{l}$ was aimed for and maintained for 60 minutes during the insulin infusion (although in 10 of the 13 patients blood glucose values fell lower than this). Surely this approach will tend to skew the results in favour of finding the glucose threshold of $2.0 \mathrm{mmol} / 1$ ? In our earlier and similar study ${ }^{1}$ in both subjects with diabetes and those without (a point which Dr Pramming and his colleagues omit to point out) a "threshold" for changes in the electroencephalogram and visual evoked responses was found to be a plasma glucose concentration of $2.6 \mathrm{mmol} / \mathrm{l}$.

The finding of no correlation between threshold and haemoglobin $A_{1 c}$ values may well be a result of a type 2 error. Studies with animals rendered chronically hyperglycaemic show a reduction in the number of glucose transporters at the bloodbrain barrier, ${ }^{2}$ with a reduction in the maximum transport capacity for glucose. ${ }^{3}$ At normoglycaemia glucose transport across the blood-brain barrier is not rate limiting for cerebral glucose metabolism; if the number of glucose transporters is reduced, however, it could become so. This may explain why some diabetics have symptoms of 